\title{
Secondary Interactions in Crystals of all Ten Isomers of Di(bromomethyl)naphthalene
}

Peter G. Jones ${ }^{a}$ and Piotr Kuś ${ }^{b}$

${ }^{a}$ Institut für Anorganische und Analytische Chemie, Technische Universität Braunschweig, Postfach 3329, 38023 Braunschweig, Germany

b Department of Chemistry, University of Silesia, 9, Szkolna Street, 40-006 Katowice, Poland

Reprint requests to Prof. Dr. P. G. Jones. Fax: +49-531-391-5387. E-mail: p.jones@tu-bs.de

Z. Naturforsch. 2010, 65b, 433-444; received January 19, 2010

Dedicated to Professor Wolf-Walter du Mont on the occasion of his $65^{\text {th }}$ birthday

The packing of all ten isomers of di(bromomethyl)naphthalene is analysed; nine of the structures were determined here, one (the 1,8-isomer) was already known. The 1,5- and 2,6-isomers display crystallographic inversion symmetry and the 2,7-isomer mirror symmetry through the central bond. For the 1,2-, 1,7- and 2,7-isomers, the bromomethyl groups point to the same side of the ring system, and for all other isomers to opposite sides. As expected, the molecules are linked into aggregates by various types of interactions: weak hydrogen bonds $\mathrm{CH} \cdots \mathrm{Br}, \mathrm{Br} \cdots \mathrm{Br}$ interactions, $\mathrm{CH} \cdots \pi$ contacts, $\pi \cdots \pi$ stacking and $\mathrm{Br} \cdots \pi$ contacts. The weak hydrogen bonds tend to be numerous but relatively long, and do not combine to form readily recognisable patterns; a more readily assimilated view of the packing is based on the $\mathrm{Br} \cdots \mathrm{Br}$ interactions, which are observed for all isomers except 1,7 and 2,3, and in some cases lead to aggregation to form quadrilaterals or chains. With decreasing frequency, the interactions $\pi \cdots \pi, \mathrm{C}-\mathrm{H} \cdots \pi$ and $\mathrm{Br} \cdots \pi$ are observed, but the latter are rare (just two examples) and very asymmetric, with contacts to only one or two carbons.

Key words: Di(bromomethyl)naphthalenes, Solid-state Structure, Weak Hydrogen Bonds, Bromine-Bromine Contacts

\section{Introduction}

Di(bromomethyl)naphthalenes are important substrates in the synthesis of naphthalenophanes and dithianaphthalenophanes, and also of other cyclic compounds from which various polyaromatic compounds can be obtained, such as dibenzoperylenes, benzo- pyrenes or coronenes [1]. 2,6-Di(bromomethyl)naphthalene has recently been found to have high crosslinking activity in DNA [2].

Di(bromomethyl)naphthalenes can be obtained by direct bromination of appropriate naphthalene dimethyl derivatives. Another, much safer synthetic method (avoiding the use of elemental bromine) relies

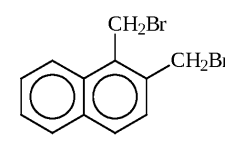

1<smiles>BrCc1ccc2c(CBr)cccc2c1</smiles>

5

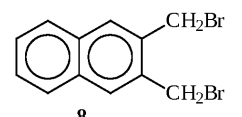

8<smiles>BrCc1cc(CBr)c2ccccc2c1</smiles>

2<smiles>BrCc1ccc2cccc(CBr)c2c1</smiles>

6<smiles>BrCc1ccc(CBr)c2ccccc12</smiles><smiles>BrCc1cccc2cccc(CBr)c12</smiles><smiles>BrCc1ccc2cc(CBr)ccc2c1</smiles><smiles>BrCc1ccc2ccc(CBr)cc2c1</smiles>

Scheme 1. 


\begin{tabular}{clllcc}
\hline Comp. & C-Br $^{\mathrm{a}}$ & $\mathrm{C}-\mathrm{C}-\mathrm{Br}^{\mathrm{a}}$ & $\mathrm{C}-\mathrm{C}-\mathrm{C}-\mathrm{Br}^{\mathrm{a}, \mathrm{b}}$ & $\begin{array}{c}\text { Disposition of } \\
\text { bromomethyl groups }^{\mathrm{b}}\end{array}$ & $\begin{array}{c}\text { Mean dev. of } \\
\text { naphthalene plane }\end{array}$ \\
\hline $\mathbf{1}$ & $1.982(3)$ & $112.4(2)$ & $82.9(3)$ & cis & 0.006 \\
& $1.979(3)$ & $110.6(2)$ & $87.1(3)$ & & \\
$\mathbf{2}$ & $1.982(2)$ & $111.8(2)$ & $78.1(2)$ & trans & 0.025 \\
& $1.981(2)$ & $110.0(2)$ & $-92.3(2)(3)$ & & \\
$\mathbf{3}$ & $1.988(2)$ & $112.5(1)$ & $80.6(2)$ & trans & 0.004 \\
& $1.983(2)$ & $109.8(1)$ & $-104.1(2)$ & & \\
$\mathbf{4}$ & $1.978(3)$ & $110.4(2)$ & $\pm 80.3(3)^{\mathrm{d}}$ & trans & 0.002 \\
$\mathbf{5}$ & $1.987(2)$ & $111.5(1)$ & $-76.5(2)$ & trans & 0.002 \\
& $1.978(2)$ & $111.8(1)$ & $107.2(2)$ & & \\
$\mathbf{6}$ & $1.985(4)$ & $111.8(3)$ & $-78.5(4)$ & cis & 0.015 \\
& $1.973(4)$ & $110.0(3)$ & $-77.5(4)$ & & \\
$\mathbf{7}$ & $1.984(6)$ & 110.9 & -77.2 & trans & 0.036 \\
& $1.974(6)$ & 112.1 & 101.8 & & \\
$\mathbf{8}$ & $1.989(2)$ & $111.1(1)$ & $97.4(2)$ & trans & 0.011 \\
& $1.981(2)$ & $112.5(1)$ & $-79.4(2)$ & & \\
$\mathbf{9}$ & $1.982(2)$ & $111.3(1)$ & $\pm 105.6(2)^{\mathrm{d}}$ & trans & 0.005 \\
$\mathbf{1 0}$ & $1.975(7)$ & $111.3(4)$ & $103.8(6)$ & cis & 0.026 \\
\hline
\end{tabular}

Table 1. Details of molecular geometry ( $\mathrm{\cap}$ and deg).

on the use of the $N$-bromosuccinimide (NBS) reagent which provides bromine radicals. In this way, suitable bromine derivatives can be obtained with high yields, and cumbersome purification procedures can often be avoided. Our studies of interactions in the solid state between bromine atoms and other constituents of various molecules have led to the synthesis of a series of bromine derivatives reported in [3-8]; cooperation with different partners involved a similar study of bromomethylated mesitylenes [9]. Continuation of these efforts resulted in the synthesis of all the isomers of di(bromomethyl)naphthalene (Scheme 1), which were subjected to crystallographic analysis. The structure of 1,8-di(bromomethyl)naphthalene has been reported [10], and is refcode BRMNAP in the Cambridge database [11]. The remaining compounds are known from the literature [12] but their crystallographic data were not available.

The isomers (Scheme 1) are numbered as compunds 1-10 in the Experimental Section and the Tables, starting with the 1,2-isomer, in the order " $1, n$ isomers then $2, n$-isomers for increasing $n$ ".

\section{Discussion}

The molecular structures are depicted in Figs. 1a10a. Except for molecules with imposed symmetry, standard naphthalene atom numbering is used; the bromomethyl substituent at the lower-numbered ring carbon is $\mathrm{C} 9-\mathrm{Br} 1$ and that at the higher-numbered carbon is $\mathrm{C} 10-\mathrm{Br} 2$. All compounds crystallise centrosymmet- rically (seven in $P 2_{1} / c$ or its alternative setting $P 2_{1} / n$ ) with no more than one molecule in the asymmetric unit. Brief optical investigations revealed no crystals of strikingly different habit that might correspond to other polymorphs; no systematic attempts to grow further polymorphs were made.

The 1,5- and 2,6-isomers display crystallographic inversion symmetry and the 2,7-isomer mirror symmetry through the central bond (here C5-C6 in crystallographic numbering). Selected molecular dimensions are summarised in Table 1. Bond lengths and angles may be regarded as normal, e.g. the shorter bonds $\mathrm{C} 1-\mathrm{C} 2, \mathrm{C} 3-\mathrm{C} 4, \mathrm{C} 5-\mathrm{C} 6$ and $\mathrm{C} 7-\mathrm{C} 8$ in the naphthalene framework, the $\mathrm{C}-\mathrm{Br}$ bond lengths (1.973$1.988 \AA$ ) and $\mathrm{C}-\mathrm{C}-\mathrm{Br}$ angles $\left(109.8-112.5^{\circ}\right)$. For the nine new structures reported here, the naphthalene ring systems are essentially planar (the largest mean deviations are $0.025 \AA$ for the 1,3-isomer and $0.026 \AA$ for the 2,7-isomer, both attributable to a slight folding of the molecule by $c a .3^{\circ}$ about the central $\mathrm{C}-\mathrm{C}$ bond). In contrast to the already reported structure of the 1,8-isomer [10], the disubstitution pattern that displays by far the worst steric crowding, there are no further distortions of the naphthalene geometry. All absolute $\mathrm{C}-\mathrm{C}-\mathrm{C}-\mathrm{Br}$ torsion angles lie in the range $75-$ $108^{\circ}$, which means that the planes of the $\mathrm{C}-\mathrm{C}-\mathrm{Br}$ units are approximately perpendicular to the ring planes, with the bromine atoms $1.6-2.0 \AA$ out of the plane; however, they may lie both on the same side of the ring system (1,2-, 1,7- and 2,7-isomers) or on opposite sides. In the 2,3- and 1,8-isomers, with vicinal or 
Table 2. C-H $\cdots$ Br hydrogen bonds ( $\AA$ and deg).

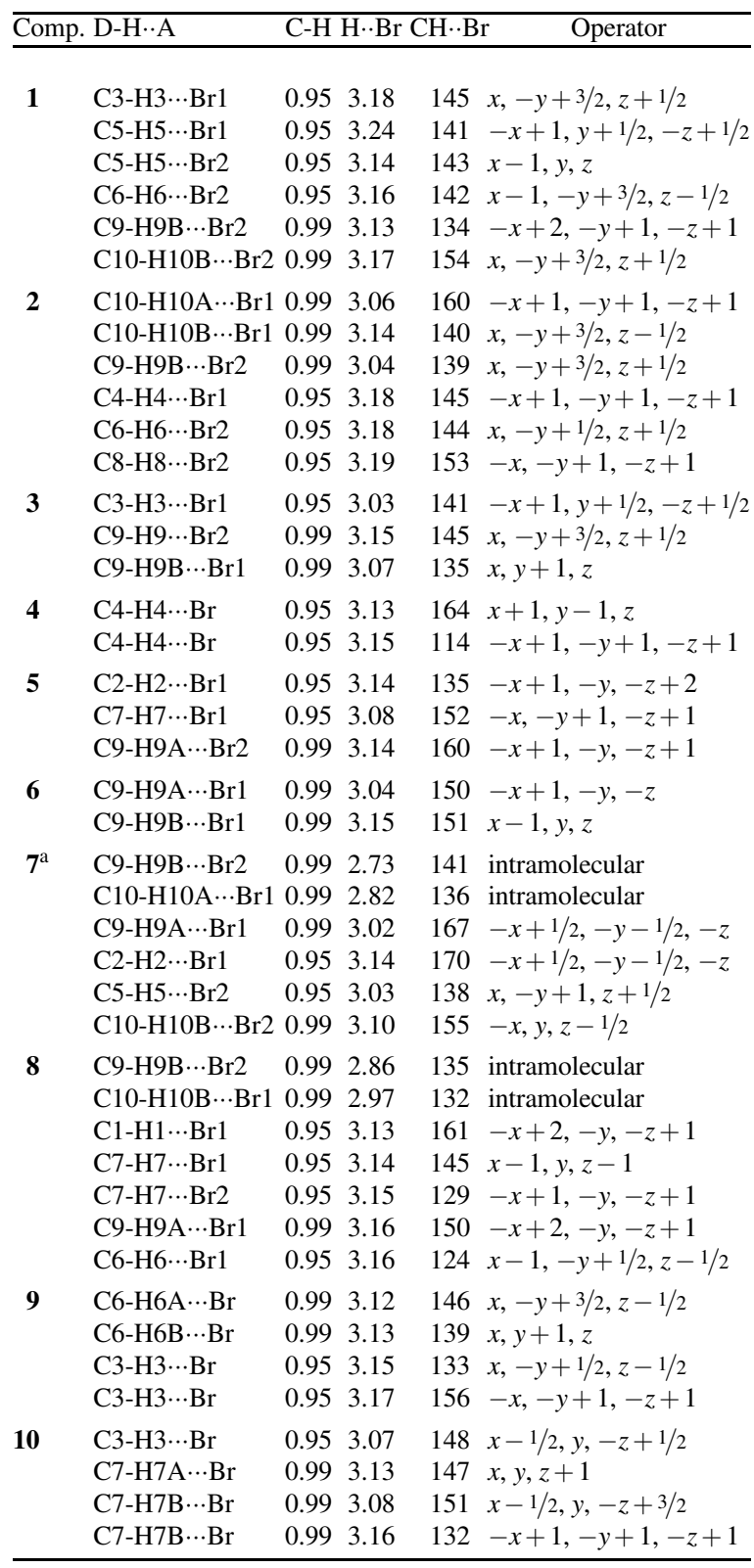

${ }^{a}$ Calculated from coordinates published in ref. [10].

effectively vicinal substitution, the latter pattern may lead to short intramolecular $\mathrm{H} \cdots \mathrm{Br}$ contacts (see below), as was pointed out for the 1,8-isomer by the original authors in terms of "electrostatic attraction" [10]; in more modern terms, these may be regarded as weak hydrogen bonds.

The main interest in the series of structures centres on the packing. In principle, up to five kinds

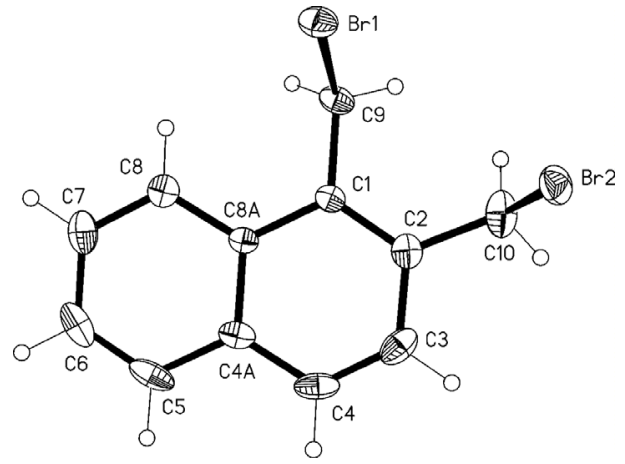

Fig. 1a. The molecule of the 1,2-isomer (1) in the crystal. Ellipsoids represent $50 \%$ probability levels; hydrogen atoms are drawn as spheres with arbitrary radii.

of secondary interaction might be expected: weak hydrogen bonds $\mathrm{C}-\mathrm{H} \cdots \mathrm{Br}$ as mentioned above (Table 2 ), $\mathrm{Br} \cdots \mathrm{Br}$ interactions (Table 3 ), $\mathrm{C}-\mathrm{H} \cdots \pi$ contacts, $\pi \cdots \pi$ stacking and $\mathrm{Br} \cdots \pi$ contacts. In the following discussion, ring 1 comprises the atoms $\mathrm{C} 1$, $\mathrm{C} 2, \mathrm{C} 3, \mathrm{C} 4, \mathrm{C} 4 \mathrm{~A}$ and $\mathrm{C} 8 \mathrm{~A}$, ring 2 the atoms $\mathrm{C} 5, \mathrm{C} 6$, $\mathrm{C} 7, \mathrm{C} 8, \mathrm{C} 4 \mathrm{~A}$ and $\mathrm{C} 8 \mathrm{~A}$. The centroids of these rings are $C g 1$ and $C g 2$. For structures possessing only one independent ring, this is ring 1 and the centroid is $C g$.

The model for $\mathrm{Br} \cdots \mathrm{Br}$ interactions is that there is a positive area in the extension of the $\mathrm{C}-\mathrm{Br}$ bond, with which a second $\mathrm{C}-\mathrm{Br}^{\delta}-$ group may then interact via its negative region cylindrically surrounding the bromine atom. Accordingly, one $\mathrm{C}-\mathrm{Br} \cdots \mathrm{Br}$ angle should be ca. $180^{\circ}$ and the other $c a .90^{\circ}$, corresponding to a type II interaction by the description of Desiraju and coworkers [13]; type I contacts, thought to represent less significant "packing effects" with at best a weak interaction, have approximately equal angles and are often formed across symmetry elements.

Some preliminary comments are in order. None of the intermolecular $\mathrm{C}-\mathrm{H} \cdots \mathrm{Br}$ contacts is very short (all $>3 \AA$, $c f$. sum of van der Waals' radii $3.05 \AA$ ). However, we have noted that the sum of several borderline interactions, which we have loosely termed "tertiary interactions", may represent a significant contribution to a stable packing pattern [14]. The nominal limit chosen here for $\mathrm{H} \cdots \mathrm{Br}$ distances is $c a .3 .17 \AA$, but some slightly longer contacts have been included because of apparent structural relevance; conversely, some contacts within this limit have been ignored because the angles are too narrow. Similar limits for $\mathrm{Br} \cdots \mathrm{Br}$ and $\mathrm{C}-\mathrm{H} \cdots \pi$ contacts are $c a .4 .1 \AA$ and $2.9 \AA$, respectively. $\mathrm{C}-\mathrm{H}$ distances are not normalised. In view of the large number of potential interactions, it 


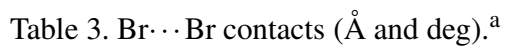

\begin{tabular}{|c|c|c|c|c|c|}
\hline Comp. & $\mathrm{C}-\mathrm{Br} \cdots \mathrm{Br}-\mathrm{C}$ & $\mathrm{Br} \cdots \mathrm{Br}$ & $\mathrm{C}-\mathrm{Br} \cdots \mathrm{Br}$ & $\mathrm{Br} \cdots \mathrm{Br}-\mathrm{C}$ & Operator \\
\hline \multirow[t]{3}{*}{1} & C9-Br1‥Br2-C10 & $3.9426(5)$ & $73.42(8)$ & $78.48(9)$ & intramolecular \\
\hline & $\mathrm{C} 9-\mathrm{Br} 1 \cdots \mathrm{Br} 2-\mathrm{C} 10$ & $3.9032(4)$ & $120.81(8)$ & $168.59(10)$ & $-x+2, y-1 / 2,-z+1 / 2$ \\
\hline & $\mathrm{C} 9-\mathrm{Br} 1 \cdots \mathrm{Br} 2-\mathrm{C} 10$ & $3.8110(4)$ & $145.16(8)$ & $82.63(9)$ & $x,-y+3 / 2, z-1 / 2$ \\
\hline \multirow[t]{2}{*}{2} & 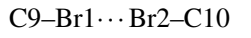 & $3.8404(5)$ & $136.99(7)$ & $126.19(7)$ & $x, y, z+1$ \\
\hline & $\mathrm{C} 9-\mathrm{Br} 1 \cdots \mathrm{Br} 2-\mathrm{C} 10$ & $4.1059(5)$ & $68.40(7)$ & $71.54(7)$ & $x,-y+3 / 2, z+1 / 2$ \\
\hline 3 & C9-Br1‥Br1-C9 & $3.5209(5)$ & $165.37(6)$ & $165.37(6)$ & $-x+1,-y+1,-z+1$ \\
\hline \multirow[t]{2}{*}{4} & $\mathrm{C} 6-\mathrm{Br} 1 \cdots \mathrm{Br} 1-\mathrm{C} 6$ & $4.0154(8)$ & 109.1(1) & 109.1(1) & $-x,-y+1,-z+1$ \\
\hline & 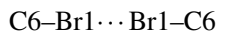 & $4.1179(8)$ & $78.1(1)$ & $78.1(1)$ & $-x,-y+2,-z+1$ \\
\hline \multirow[t]{4}{*}{$5^{b}$} & $\mathrm{C} 10-\mathrm{Br} 2 \cdots \mathrm{Br} 2-\mathrm{C} 10$ & $3.7940(5)$ & $125.00(7)$ & $125.00(7)$ & $-x,-y+1,-z$ \\
\hline & C9-Br1․ Br2-C10 & $3.9117(3)$ & $150.33(6)$ & $149.20(6)$ & $x, y, z+1$ \\
\hline & C9-Br1 $\cdots \mathrm{Br} 2-\mathrm{C} 10$ & $3.9749(4)$ & $151.89(6)$ & $72.67(7)$ & $-x,-y+1,-z+1$ \\
\hline & C9-Br1‥Br1-C9 & $4.0232(5)$ & $77.72(6)$ & $77.72(6)$ & $-x+1,-y,-z+2$ \\
\hline $7^{\mathrm{c}}$ & $\mathrm{C} 9-\mathrm{Br} 1 \cdots \mathrm{Br} 2-\mathrm{C} 10$ & 3.726 & 103.2 & 167.1 & $x,-y, z+1 / 2$ \\
\hline \multirow[t]{3}{*}{9} & C6-Br1‥Br1-C6 & $3.6571(3)$ & $169.82(5)$ & $103.04(5)$ & $-x, y-1 / 2,-z+3 / 2$ \\
\hline & C6-Br1 $\cdots B r 1-\mathrm{C}^{\mathrm{d}}$ & $3.6571(3)$ & $103.04(5)$ & $169.82(5)$ & $-x, y+1 / 2,-z+3 / 2$ \\
\hline & C6-Br1 $\cdots$ Br1-C6 & $3.8914(4)$ & $78.56(5)$ & $78.56(5)$ & $-x,-y+1,-z+1$ \\
\hline \multirow[t]{3}{*}{10} & 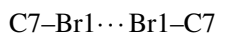 & $3.640(1)$ & $101.5(2)$ & $168.0(2)$ & $-x+3 / 2,-y+1, z+1 / 2$ \\
\hline & $\mathrm{C} 7-\mathrm{Br} 1 \cdots \mathrm{Br} 1-\mathrm{C}^{\mathrm{d}}$ & $3.640(1)$ & $168.0(2)$ & $101.5(2)$ & $-x+3 / 2,-y+1, z-1 / 2$ \\
\hline & $\mathrm{C} 7-\mathrm{Br} 1 \cdots \mathrm{Br} 1-\mathrm{C} 7$ & $3.886(1)$ & $75.57(2)$ & $75.6(2)$ & $-x+1,-y+1,-z+1$ \\
\hline
\end{tabular}

${ }^{a}$ There are no such interactions for compounds $\mathbf{6}$ and $\mathbf{8}$; ${ }^{b}$ angles within $\mathrm{Br}_{3}$ triangles: at $\mathrm{Br} 157.50(1)$, at $\mathrm{Br} 2$ 60.41(1) and $62.08(1)^{\circ}$; ${ }^{c}$ calculated from coordinates published in ref. [10]; ${ }^{\mathrm{d}}$ symmetry-equivalent to previous interaction.

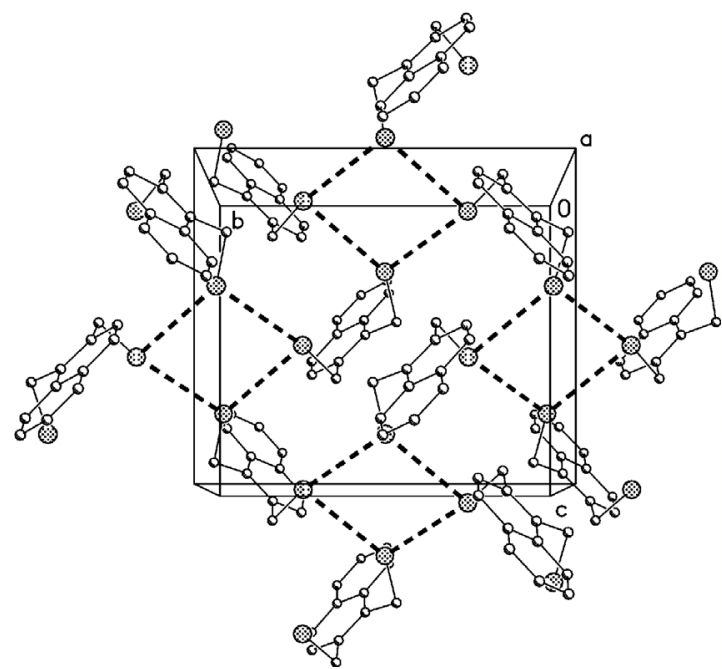

Fig. 1b. Packing diagram of compound 1 viewed perpendicular to the $y z$ plane in the region $x \approx 0$. Thick dashed lines represent $\mathrm{Br} \cdots \mathrm{Br}$ interactions.

is seldom the case that a small number of stronger interactions dominate the packing, and the choice of a hierarchy of interactions may therefore be subjective.

In the packing of the 1,2-isomer (Fig. 1b) the bromine atoms occupy the regions $x \approx 0,1, \ldots$ and are involved in six $\mathrm{C}-\mathrm{H} \cdots \mathrm{Br}$ and two $\mathrm{Br} \cdots \mathrm{Br}$ interactions. The latter do not correspond well to either ideal type, but are closer to type II, and thus probably corre-

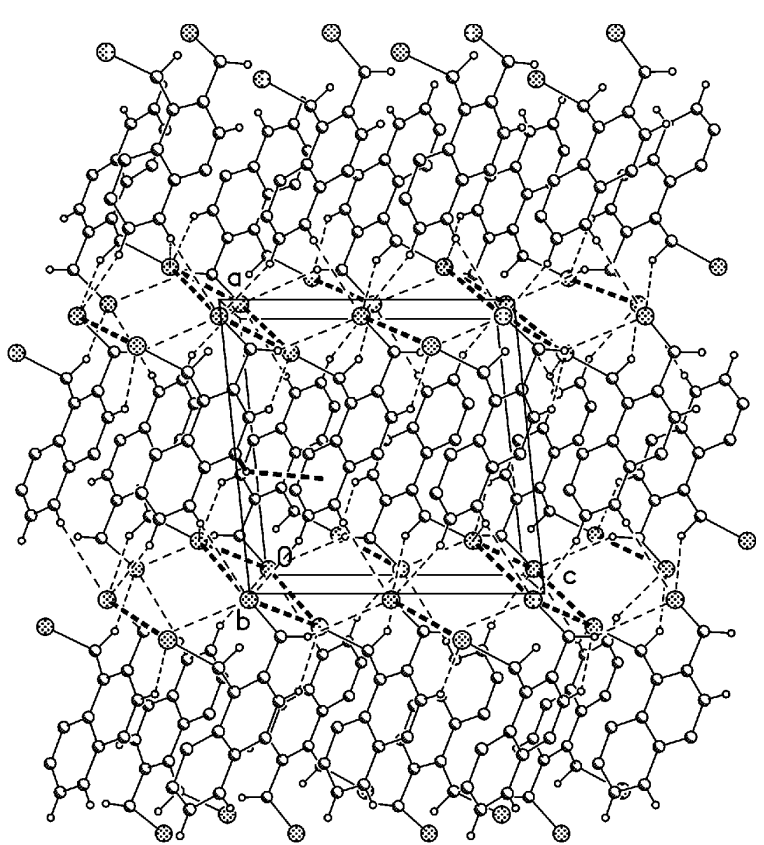

Fig. 1c. Packing diagram of compound 1 viewed along the $y$ axis. Thin dashed lines represent $\mathrm{H} \cdots \mathrm{Br}$ and thick dashed lines $\mathrm{Br} \cdots \mathrm{Br}$ interactions. One representative $\mathrm{H} \cdots \pi$ interaction is included (thick dashed line, centre left).

spond to fairly weak interactions (consistent with the $\mathrm{Br} \cdots \mathrm{Br}$ distances, which are appreciably longer than the double van der Waals' radius 3.7 $\AA$ ). The molecules 
associate across inversion centres to form approximate squares of bromine atoms (angles $87,93^{\circ}$ ), connecting the molecules to form layers parallel to the crystallographic $y z$ plane (Fig. 1b); only one of the $\mathrm{H} \cdots \mathrm{Br}$ contacts $(\mathrm{H} 9 \mathrm{~B} \cdots \mathrm{Br} 2)$ is involved in this layer and is not shown in Fig. 1b. The layers at $x \approx 0$ and $x \approx 1$ interdigitate via the remaining $\mathrm{H} \cdots \mathrm{Br}$ interactions and also via a $\pi \cdots \pi$ interaction between pairs of ring systems related by the inversion operator $1-x, 1-y, 1-z$, with $C g 1 \cdots C g 13.80 \AA$ (vertical $3.39 \AA$ ) and $C g 1 \cdots C g 2$ $3.75 \AA$ (vertical $3.40 \AA$ ). Finally, there is one borderline $\mathrm{C} 4-\mathrm{H} 4 \cdots \mathrm{Cg} 2$ interaction $(\mathrm{H} \cdots \mathrm{Cg} 22.96 \AA$, angle $135^{\circ}$, operator $\left.x,-y+3 / 2, z+1 / 2\right)$. The overall packing is complex, but is included for completeness as Fig. 1c, in which the general features of the packing can be recognised.

The packing of the 1,3-isomer (Fig. 2b) is also quite complex, although involving thick double layers (one per $x$ axis repeat) rather than a three-dimensional

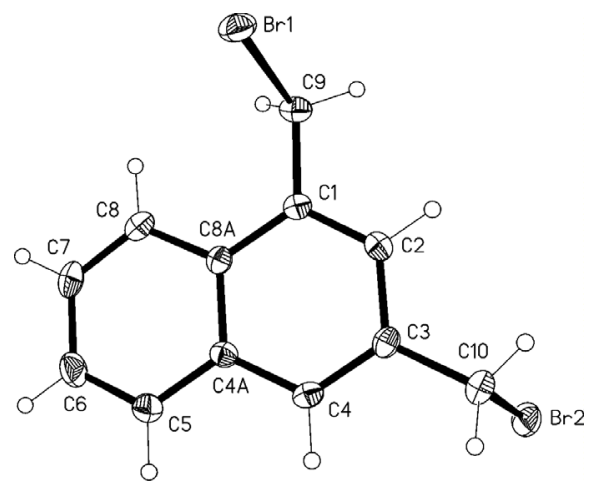

Fig. 2a. The molecule of the 1,3-isomer (2) in the crystal. Ellipsoids represent $50 \%$ probability levels; hydrogen atoms are drawn as spheres with arbitrary radii.

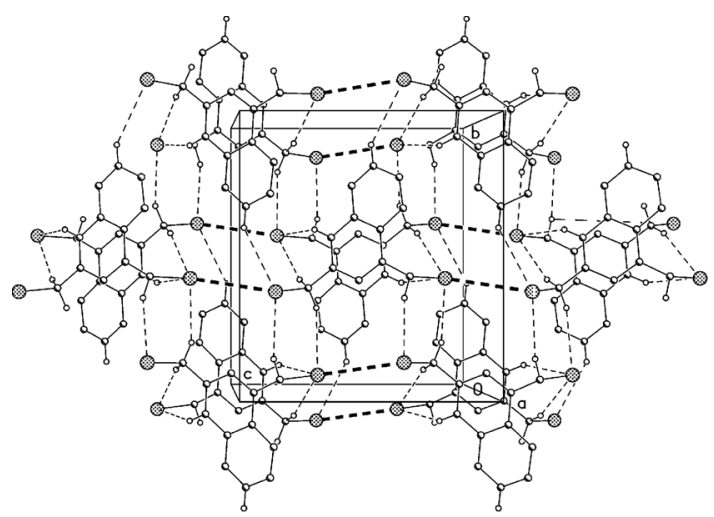

Fig. 2b. Packing diagram of compound $\mathbf{2}$ viewed perpendicular to the $y z$ plane. Thin dashed lines represent longer $\mathrm{H} \cdots \mathrm{Br}$, thick dashed lines $\mathrm{Br} \cdots \mathrm{Br}$ interactions. pattern. The clearest substructure is a double chain of molecules parallel to the $z$ axis (horizontal in Fig. 2b), linked by the only $\mathrm{Br} \cdots \mathrm{Br}$ interaction (type I, via $z$ axis translation) and by a $\pi \cdots \pi$ interaction via the inversion centre $1-x, 1-y, 1-z$, with $C g 1 \cdots C g 13.63 \AA$ (vertical $3.29 \AA$ ), clearly recognisable $e$. $g$. in the centre of the cell. This substructure is supported by the shortest five of six $\mathrm{C}-\mathrm{H} \cdots \mathrm{Br}$ contacts to form a double layer. The long $\mathrm{Br} 1 \cdots \mathrm{Br} 2$ contact $(4.11 \AA$ ) between adjacent chains is probably of little relevance and is excluded from the Figure. The double layers are connected in the $x$ direction by the sixth $\mathrm{C}-\mathrm{H} \cdots \mathrm{Br}$ contact and by the C9-H9 $\cdots C g 1$ interaction $(\mathrm{H} \cdots C g 12.61 \AA$,

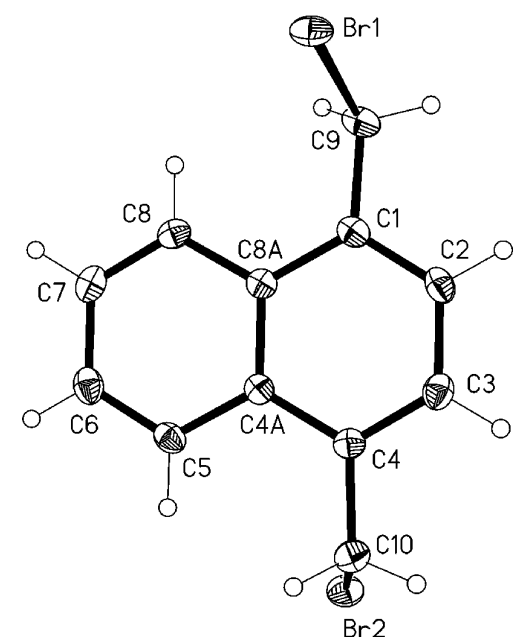

Fig. 3a. The molecule of the 1,4-isomer (3) in the crystal. Ellipsoids represent $50 \%$ probability levels; hydrogen atoms are drawn as spheres with arbitrary radii.

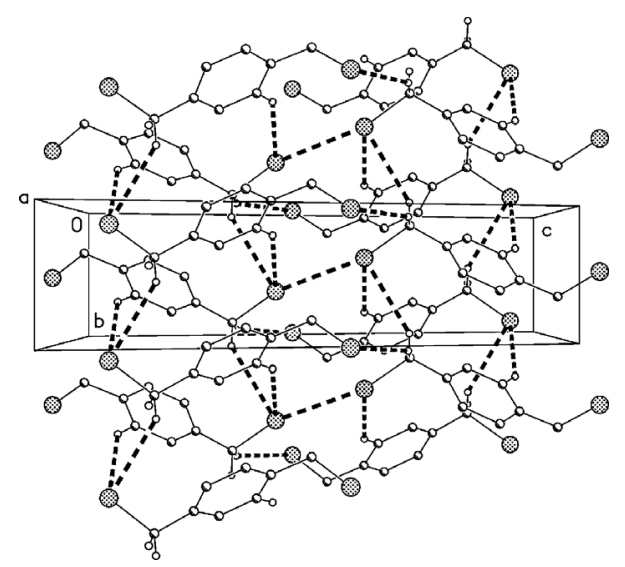

Fig. 3b. Packing diagram of compound $\mathbf{3}$ viewed parallel to the $x$ axis. Thick dashed lines represent $\mathrm{H} \cdots \mathrm{Br}$ or $\mathrm{Br} \cdots \mathrm{Br}$ interactions. The ring atoms $\mathrm{C} 5,6,7,8$ are omitted for clarity, so that the naphthalene moieties appear as single rings. 


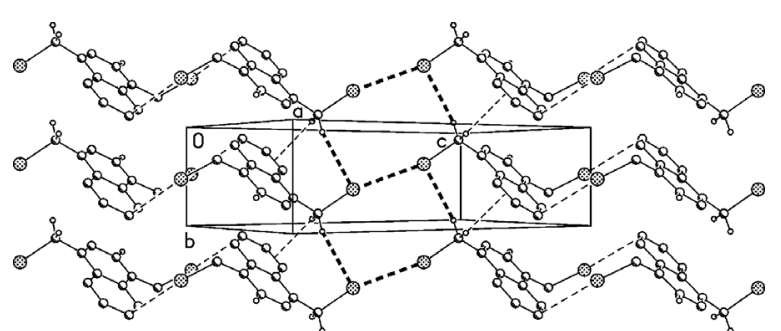

Fig. 3c. Packing diagram of compound $\mathbf{3}$ viewed perpendicular to $(10 \overline{1})$. Thick dashed lines represent $\mathrm{H} \cdots \mathrm{Br}$ or $\mathrm{Br} \cdots \mathrm{Br}$ interactions. Thin dashed lines indicate "unusual" $\mathrm{H} \cdots \pi$ or $\mathrm{Br} \cdots \mathrm{C}$ interactions (see text). Interactions at the left- and right-hand edges of the diagram are not drawn explicitly.

angle $127^{\circ}$, operator $-x, 1-y, 1-z$ ); these too are not shown in the Figure.

The packing of the 1,4-isomer (Fig. 3b) is conceptually much simpler but still quite complex to view because it forms thick layers (one per $x$ axis repeat). There are only three $\mathrm{C}-\mathrm{H} \cdots \mathrm{Br}$ contacts and only one $\mathrm{Br} \cdots \mathrm{Br}$ interaction, which, despite its being very short, is a type I interaction by symmetry. The structure is however easier to comprehend if it is viewed as a thin slice perpendicular to $(10 \overline{1})$ (Fig. 3c). It is easily seen that the $\mathrm{Br} \cdots \mathrm{Br}$ interaction combines with $\mathrm{H} 9 \mathrm{~B} \cdots \mathrm{Br} 1$ to form a ribbon parallel to the short $y$ axis. Two more unusual contacts can also be seen: first, within the ribbons, from H9B to the midpoint of C7-C8 (2.72 A, interpretable as a peripheral $\mathrm{H} \cdots \pi$ interaction); secondly, a Br2 ․ C6 contact between adjacent ribbons of only $3.422(2) \AA$, with an angle of $169.16(7)^{\circ}$. It is tempting to suggest that this is an incipient and highly asymmetric $\mathrm{Br} \cdots \pi$ interaction.

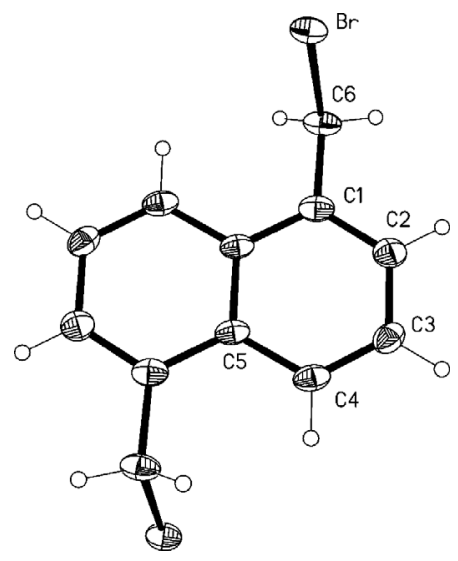

Fig. 4a. The molecule of the 1,5-isomer (4) in the crystal. Ellipsoids represent $50 \%$ probability levels; hydrogen atoms are drawn as spheres with arbitrary radii. Only the asymmetric unit is numbered.

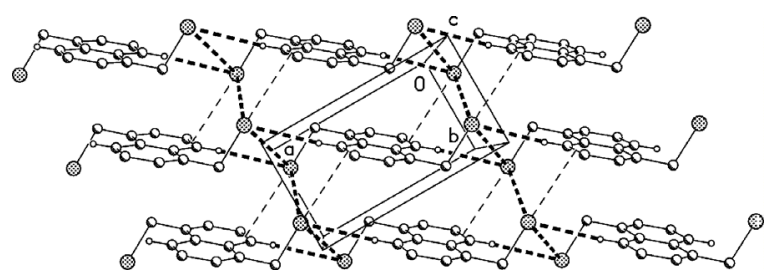

Fig. 4b. Packing diagram of compound 4 viewed perpendicular to the $x y$ plane in the region $z \approx 1 / 2$. Thin dashed lines represent $\mathrm{Br} \cdots \pi$, thick dashed lines $\mathrm{H} \cdots \mathrm{Br}$ or $\mathrm{Br} \cdots \mathrm{Br}$ interactions.

The inversion-symmetric molecule of the 1,5-isomer, packs so as to form a layer structure parallel to the $x y$ plane in the regions $z \approx 0,1 / 2$, etc. (Fig. 4b). Molecules are linked by one $\mathrm{C}-\mathrm{H} \cdots \mathrm{Br}$, two long $\mathrm{Br} \cdots \mathrm{Br}$ (type I) and one $\mathrm{Br} \cdots \pi$ interaction. The bromine atoms form zigzag chains parallel to the $y$ axis with angles of $67.99(2)^{\circ}$ and lie in the regions $x \approx 0$, $1, \ldots$ for the layer pictured (but at $x \approx \pm 1 / 2, \ldots$ for adjacent layers). The acceptor of the $\mathrm{Br} \cdots \pi$ interaction is the midpoint of the bond $\mathrm{C} 3-\mathrm{C} 4$ rather than the ring centroid ( $\mathrm{Br} \cdots$ midpoint $3.47 \AA$, angle $176^{\circ}$ ); the linearity is consistent with the interaction of a $\pi$ cloud with the positive extension of the $\mathrm{C}-\mathrm{Br}$ bond. Three $\mathrm{H} \cdots \mathrm{Cg}$ distances involving the hydrogens at $\mathrm{C} 6$ lie in the range $3.04-3.15 \AA$, but two of them have angles less than $110^{\circ}$. They are not included in the Figure.

The packing of the 1,6-isomer is three-dimensional, but the three shortest $\mathrm{Br} \cdots \mathrm{Br}$ contacts (of four) and the shortest $\mathrm{H} \cdots \mathrm{Br}$ contact (of three) combine to form strongly corrugated ribbons with overall direction parallel to the $z$ axis (Fig. 5b). The bromine atoms assemble in the regions $z \approx 0,1, \ldots$, to form exactly planar rhombi consisting of two almost equilateral triangles with a shorter common edge $\mathrm{Br} 2 \cdots \mathrm{Br} 2$. Two of the interactions are type I and one $(\mathrm{Br} 1 \cdots \mathrm{Br} 23.9749(4) \AA$

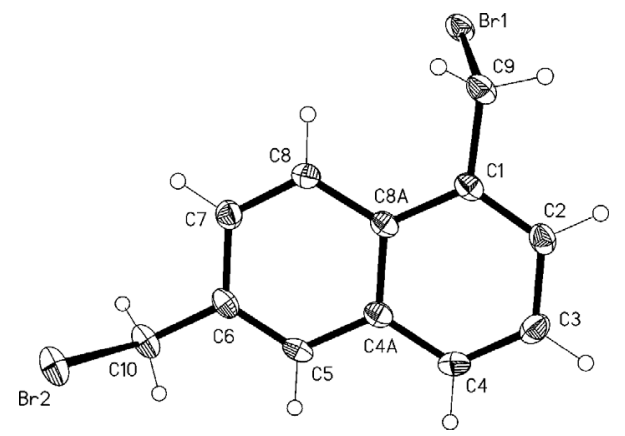

Fig. 5a. The molecule of the 1,6-isomer (5) in the crystal. Ellipsoids represent $50 \%$ probability levels; hydrogen atoms are drawn as spheres with arbitrary radii. 


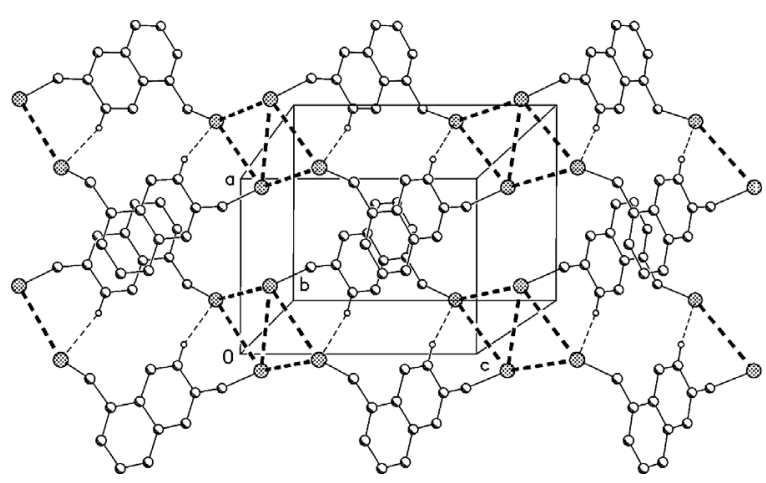

Fig. 5b. Packing diagram of compound 5 viewed perpendicular to the $x z$ plane. Thin dashed lines represent $\mathrm{H} \cdots \mathrm{Br}$, thick dashed lines $\mathrm{Br} \cdots \mathrm{Br}$ interactions.

- not the shortest!) is type II. The ribbons overlap (e. g. in the centre of the cell) with contacts $C g 1 \cdots C g 2$ $3.82 \AA$ (vertical $3.43 \AA$ ) and $C g 2 \cdots C g 23.88 \AA$ (vertical $3.43 \AA$ ).

The 1,7-isomer has surprisingly few contacts. The packing diagram (Fig. 6b) shows the ribbons paral-

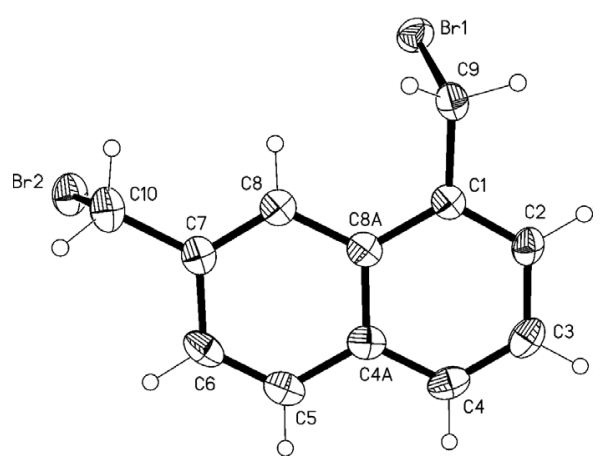

Fig. 6a. The molecule of the 1,7-isomer (6) in the crystal. Ellipsoids represent $50 \%$ probability levels; hydrogen atoms are drawn as spheres with arbitrary radii.

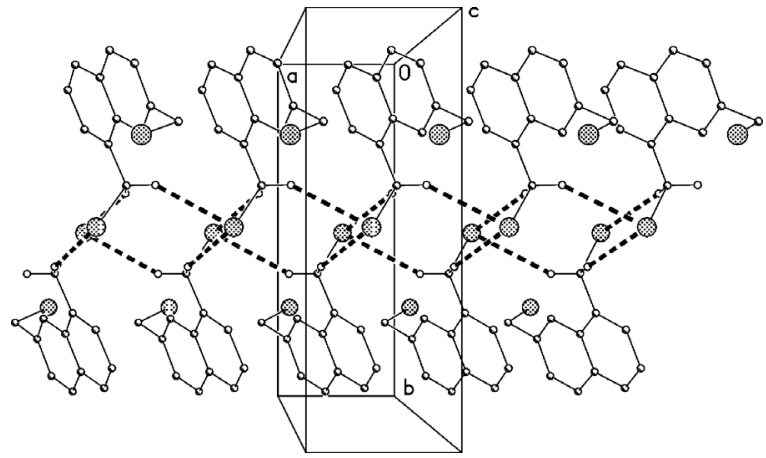

Fig. 6b. Packing diagram of compound 6 viewed perpendicular to the $x y$ plane. Thick dashed lines represent $\mathrm{H} \cdots \mathrm{Br}$ interactions. lel to the $x$ axis that are formed by the two shortest $\mathrm{H} \cdots \mathrm{Br}$ contacts, both involving the methylene group at C9 (one via $x$ axis translation, one via inversion forming rings of graph set $\mathrm{R}_{2}^{2}(6)$ ). Within the ribbon the rings overlap significantly via $x$ axis translation, with $C g 1 \cdots C g 23.75 \AA$ (vertical $3.40 \AA$ ) and an interplanar angle of $1^{\circ}$. There are no $\mathrm{Br} \cdots \mathrm{Br}$ contacts $<4.2 \AA$. The only short $\mathrm{C}-\mathrm{H} \cdots \pi$ contact of $2.9 \AA$ has a narrow angle $\left(112^{\circ}\right)$.

The 1,8-isomer [10] displays one short $\mathrm{Br} \cdots \mathrm{Br}$ interaction of classical type II, which combines with three of the four $\mathrm{H} \cdots \mathrm{Br}$ contacts (excluding $\mathrm{H} 10 \mathrm{~B} \cdots \mathrm{Br} 2)$ to form thick layers parallel to the $y z$ plane (Fig. $7 b$ ) at $x \approx 1 / 4,3 / 4$, etc. Within the in-

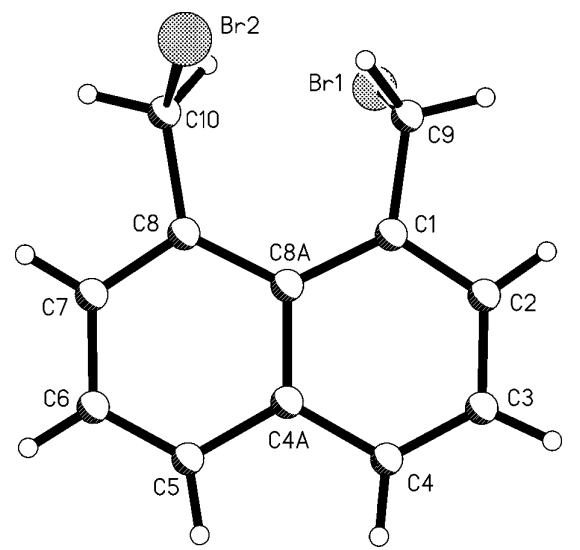

Fig. 7a. The molecule of the 1,8-isomer (7) in the crystal. The coordinates published in ref. [10] were used but the numbering scheme was changed to be consistent with this paper; furthermore, $\mathrm{C}-\mathrm{H}$ bond lengths, which showed appreciable scatter, were normalised to $0.99 \AA$ for methylene and $0.95 \AA$ for aromatic hydrogen atoms. Atom radii are arbitrary.

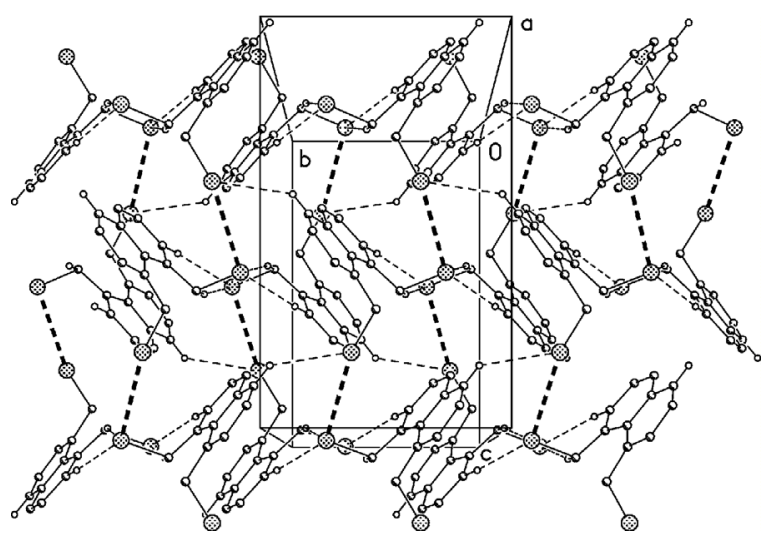

Fig. 7b. Packing diagram of compound 7 viewed perpendicular to the $y z$ plane in the region $x \approx 1 / 4$. Thick dashed lines represent $\mathrm{Br} \cdots \mathrm{Br}$ and thin dashed lines $\mathrm{H} \cdots \mathrm{Br}$ interactions. 
dividual layers (at $x \approx 1 / 8,3 / 8,5 / 8,7 / 8$ ) the molecules are hexagonally packed and the $\mathrm{Br} \cdot \mathrm{Br}$ contact (via the $c$ glide plane) links molecules to form chains with overall direction parallel to the $z$ axis.

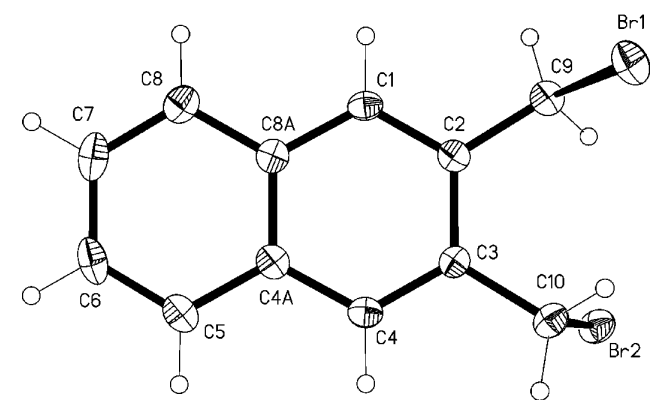

Fig. 8a. The molecule of the 2,3-isomer (8) in the crystal. Ellipsoids represent $50 \%$ probability levels; hydrogen atoms are drawn as spheres with arbitrary radii.

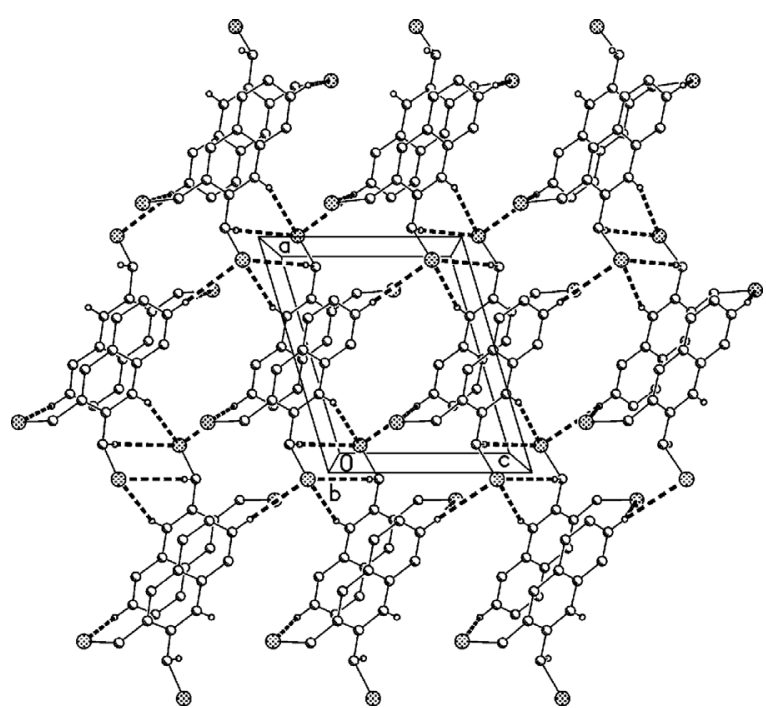

Fig. 8b. Packing diagram of compound $\mathbf{8}$ viewed parallel to the $y$ axis in the region $y \approx 1 / 2$. Thick dashed lines represent $\mathrm{H} \cdots \mathrm{Br}$ interactions.

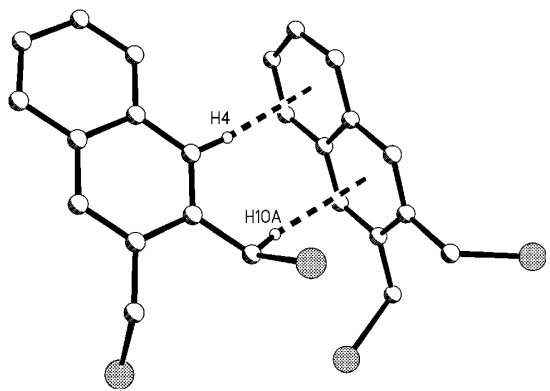

Fig. 8c. Compound 8: $\mathrm{C}-\mathrm{H} \cdots \pi$ interactions. $\mathrm{H} 4 \cdots C g 22.85 \AA, 167^{\circ}$ and $\mathrm{H} 10 \mathrm{~A} \cdots C g 12.72 \AA, 159^{\circ}$.
The 2,3-isomer forms double layers parallel to the $x z$ plane in the regions $y \approx 0,1 / 2$, etc. (Fig. 8b). These involve the four shortest $\mathrm{H} \cdots \mathrm{Br}$ contacts. Within the double layers, $C g 1 \cdots C g 2$ contacts of $3.92 \AA$ (vertical $3.40 \AA$ ) across inversion centres may be relevant, although the offset is quite large at $1.95 \AA$. Between the double layers, two $\mathrm{C}-\mathrm{H} \cdots \pi$ contacts via the $c$ glide operator are striking (Fig. 8c). Within the individual layers (at $y \approx 1 / 8,3 / 8,5 / 8,7 / 8$ ) the molecules are hexagonally packed. There are no $\mathrm{Br} \cdots \mathrm{Br}$ contacts $<4.3 \AA$.

The inversion-symmetric 2,6-isomer contains only one independent bromine atom, but this is involved in no fewer than three (only two independent) $\mathrm{Br} \cdots \mathrm{Br}$

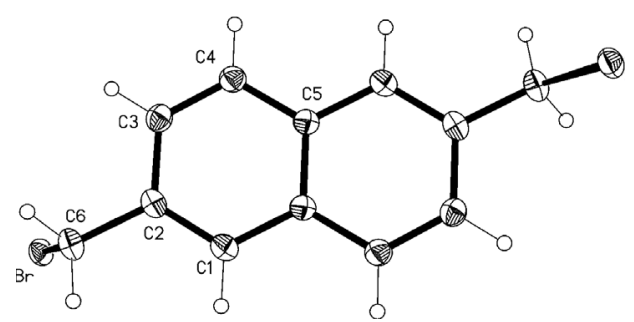

Fig. 9a. The molecule of the 2,6-isomer (9) in the crystal. Ellipsoids represent $50 \%$ probability levels; hydrogen atoms are drawn as spheres with arbitrary radii. Only the asymmetric unit is numbered.

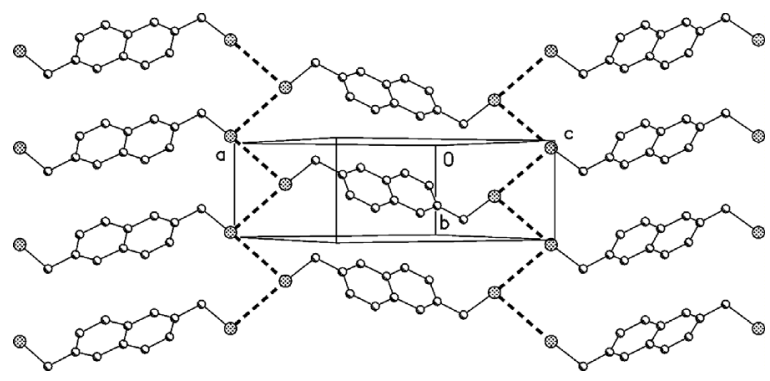

Fig. 9b. Packing diagram of compound 9 viewed perpendicular to (102). Thick dashed lines represent $\mathrm{Br} \cdots \mathrm{Br}$ interactions.

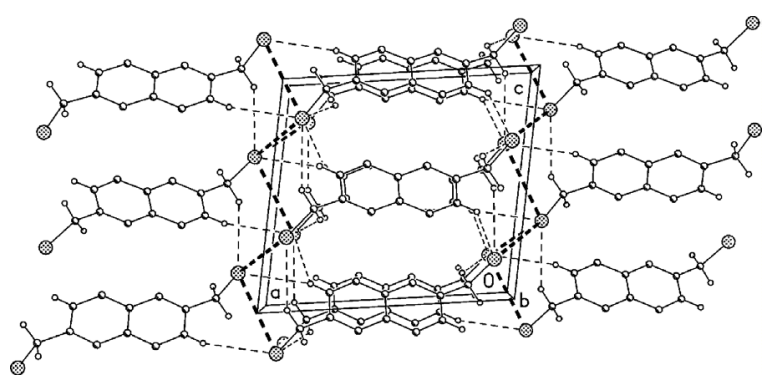

Fig. 9c. Packing diagram of compound 9 viewed parallel to the $y$ axis, giving an overview of the three-dimensional packing. Thick dashed lines represent $\mathrm{Br} \cdots \mathrm{Br}$ and thin dashed lines $\mathrm{H} \cdots \mathrm{Br}$ interactions. 
and four $\mathrm{H} \cdots \mathrm{Br}$ interactions. The shortest $\mathrm{Br} \cdots \mathrm{Br}$ contact (via the $2_{1}$ screw axis) is a typical type II interaction and connects the molecules to form layers parallel to (102) (Fig. 9b). In the zigzag chains of bromine atoms thus formed (overall direction parallel to $y$ ) the $\mathrm{Br} \cdots \mathrm{Br} \cdots \mathrm{Br}$ angle is $80.88(1)^{\circ}$. The bromine atoms occupy the regions $x \approx 0,1, \ldots$; the view parallel to the short $y$ axis (Fig. 9c) gives an impression of the large number of secondary contacts in these regions.

The packing of the mirror-symmetric 2,7-isomer is very similar to that of the 2,6-isomer. The shortest $\mathrm{Br} \cdots \mathrm{Br}$ contact (via a $2{ }_{1}$ screw axis parallel to $z$ ) is

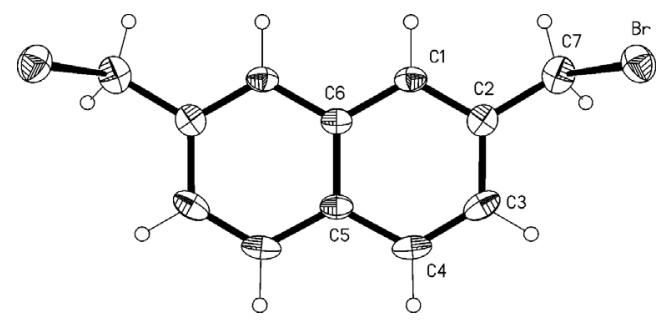

Fig. 10a. The molecule of the 2,7-isomer (10) in the crystal. Ellipsoids represent $50 \%$ probability levels; hydrogen atoms are drawn as spheres with arbitrary radii. Only the asymmetric unit is numbered.

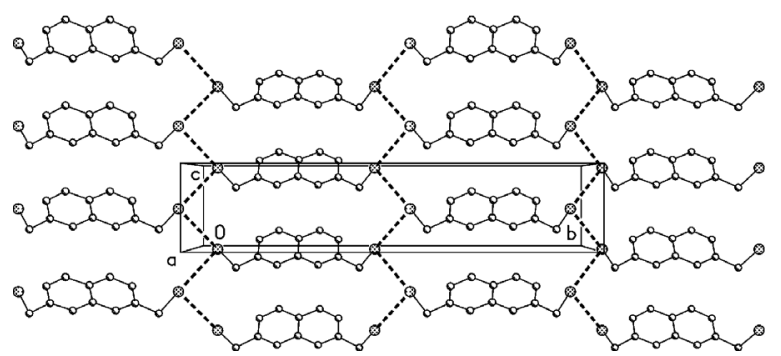

Fig. 10b. Packing diagram of compound $\mathbf{1 0}$ viewed parallel to the $x$ axis in the region $x \approx 0$ to $1 / 2$. Molecules in the first and third vertical columns lie at $x \approx 1 / 2$ and those in the second and fourth columns at $x \approx 0$. Thick dashed lines represent $\mathrm{Br} \cdots \mathrm{Br}$ interactions.

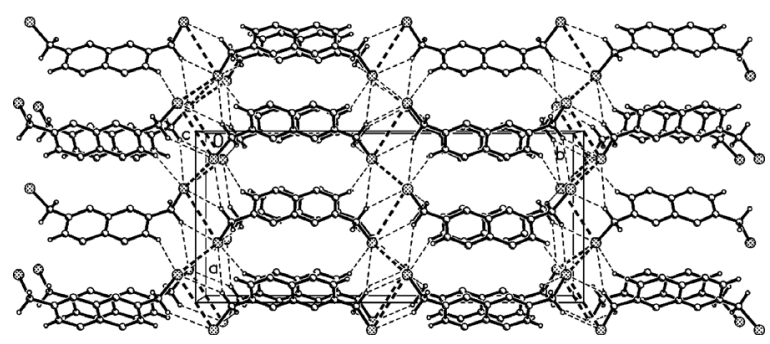

Fig. 10c. Packing diagram of compound $\mathbf{1 0}$ viewed parallel to the $z$ axis, giving an overview of the three-dimensional packing. The layers of Fig. 10b undulate through this diagram. Thick dashed lines represent $\mathrm{Br} \cdots \mathrm{Br}$ and thin dashed lines $\mathrm{H} \cdots \mathrm{Br}$ interactions. again a typical type II interaction and connects the molecules to form corrugated layers parallel to the $y z$ plane (Fig. 10b). In the zigzag chains of bromine atoms (overall direction parallel to $z$ ) the $\mathrm{Br} \cdots \mathrm{Br} \cdots \mathrm{Br}$ angle is $82.98(3)^{\circ}$. The bromine atoms occupy the regions $y \approx 0,1 / 2,1, \ldots$; the view parallel to the short $x$ axis (Fig. 10c) shows the secondary contacts in these regions.

Attempts to summarise and generalise the packing features for all ten isomers reveal limited similarities. As might be expected, all structures display a number of $\mathrm{C}-\mathrm{H} \cdots \mathrm{Br}$ interactions (from two to six, depending how the criteria are defined). The defining feature of the molecular packing was expected to be the presence of $\mathrm{Br} \cdots \mathrm{Br}$ contacts, and these indeed appear in all but two of the structures. However, the distances are variable $(3.5-4.1 \AA)$ and the shortest do not necessarily correspond, as one might have expected, to type II contacts, which are more readily interpreted as genuine interactions. Indeed, the shortest contact (in the 1,4-isomer) is definitely type I, whereas some of the longest (e.g. in the 1,5 -isomer) seem to have important structure-determining roles. In some cases, the bromine atoms aggregate, thereby forming quadrilaterals in the 1,2- and 1,6-isomers, but chains in the 1,5-, 2,6- and 2,7-isomers. The importance of the $\mathrm{C}-\mathrm{H} \cdots \mathrm{Br}$ and $\mathrm{Br} \cdots \mathrm{Br}$ contacts is shown by the formation of regions, often at the cell boundaries, in which these contacts are concentrated. With decreasing frequency, the further types of interaction $\pi \cdots \pi$ (unsurprising in view of the dominance of naphthalene rings), $\mathrm{C}-\mathrm{H} \cdots \pi$ and $\mathrm{Br} \cdots \pi$ are observed, but the latter are rare (just two examples) and very asymmetric, with contacts to only one or two carbon atoms. One may conclude that the observed packing patterns seem to be logical but would be difficult to predict in detail; however, in view of the limited number of degrees of torsional freedom (effectively only one, the position of the bromine atoms displaced to one or both sides of the ring system), these systems might pose an interesting challenge to structure-predicting programs [15].

\section{Experimental Section}

All isomers (for compound numbering see Scheme 1) were obtained from the corresponding dimethylnaphthalene derivatives by radical bromination with NBS in carbon tetrachloride. Physical and chemical data of the compounds obtained were in agreement with reference data. Selected NMR and other data are summarised below, because in the original publication [12] much of this information was necessar- 


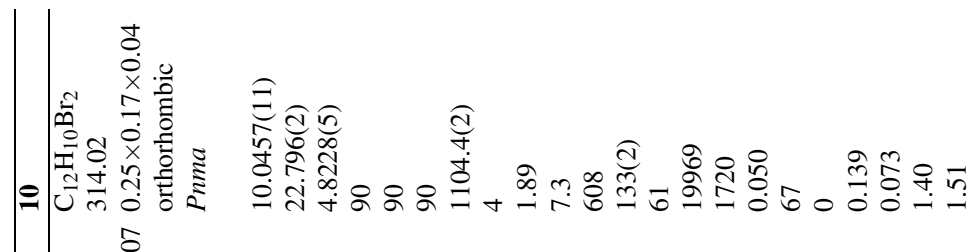

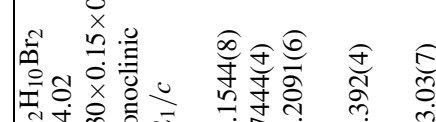

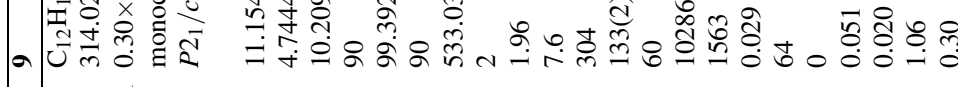
‡:

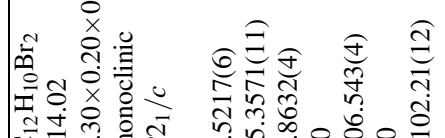

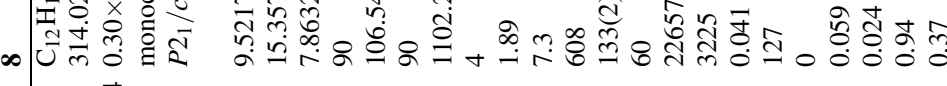
¿্.

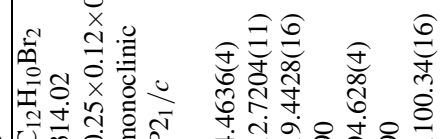

- U一ल 0
$\dot{0}$
$\dot{x}$
$\infty$
0

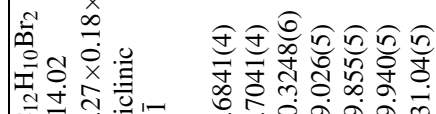

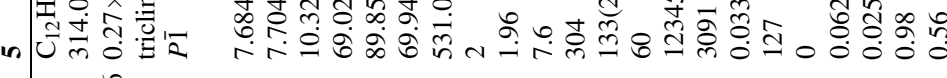
$\stackrel{8}{\circ}$

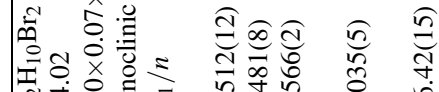

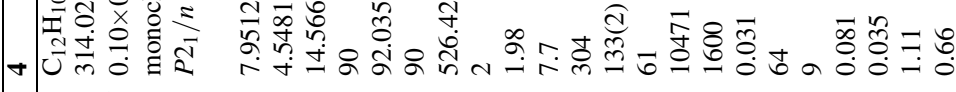
:

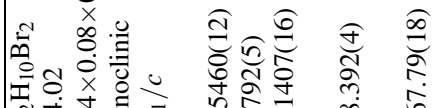

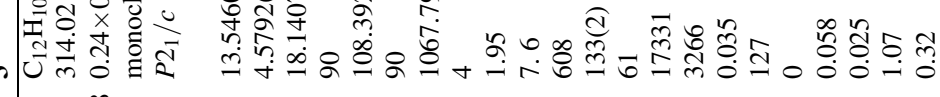

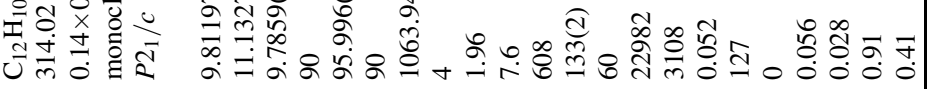
苜 
ily missing. Data for the 1,8-isomer 7 were given in [10], but without ${ }^{13} \mathrm{C}$ NMR data. Single crystals used in crystallographic studies were obtained by slow evaporation of solutions: 1,2-, 1,5- and 2,6-isomers $(\mathbf{1}, \mathbf{4}, \mathbf{9})$ from chloroform, 1,3- and 1,4-isomers $(\mathbf{2}, \mathbf{3})$ from methanol/acetone, 1,6-, 1,7-, 2,3- and 2,7-isomers $(\mathbf{5}, \mathbf{6}, \mathbf{8}, \mathbf{1 0})$ from carbon tetrachloride.

1: M.p. $149-151{ }^{\circ} \mathrm{C} .-{ }^{1} \mathrm{H}$ NMR (500 $\left.\mathrm{MHz}, \mathrm{CDCl}_{3}\right)$ : $\delta=8.15(\mathrm{~d}, 1 \mathrm{H}), 7.86(\mathrm{~d}, 1 \mathrm{H}), 7.30(\mathrm{~d}, 1 \mathrm{H}), 7.65(\mathrm{t}, 1 \mathrm{H})$, $7.55(\mathrm{t}, 1 \mathrm{H}), 7.43(\mathrm{~d}, 1 \mathrm{H}), 5.11(\mathrm{~s}, 2 \mathrm{H}), 4.77(\mathrm{~s}, 2 \mathrm{H})$. ${ }^{13} \mathrm{C}$ NMR $(100 \mathrm{MHz}): \delta=25.56,30.67,123.75,126.87$, $127.44,127.95,128.92,130.18,131.65,132.22,133.96$, 134.60 .

2: M.p. $114-116{ }^{\circ} \mathrm{C} .-{ }^{1} \mathrm{H}$ NMR $\left(500 \mathrm{MHz}, \mathrm{CDCl}_{3}\right): \delta=$ $8.13(\mathrm{~d}, 1 \mathrm{H}), 7.86(\mathrm{~d}, 1 \mathrm{H}), 7.83(\mathrm{~s}, 1 \mathrm{H}), 7.63(\mathrm{t}, 1 \mathrm{H}), 7.58(\mathrm{~d}$, $1 \mathrm{H}), 7.55(\mathrm{t}, 1 \mathrm{H}) .-{ }^{13} \mathrm{C}$ NMR $(100 \mathrm{MHz}): \delta=31.18,33.42$, $123.86,127.01,127.42,128.62,129.08,129.62,130.87$, 134.03, 134.45, 134.79.

3: M. p. $190-192{ }^{\circ} \mathrm{C} .-{ }^{1} \mathrm{H}$ NMR $\left(500 \mathrm{MHz}, \mathrm{CDCl}_{3}\right): \delta=$ $8.20-8.23$ and $7.66-7.69\left(\mathrm{AA}^{\prime} \mathrm{BB}^{\prime}, 4 \mathrm{H}\right), 7.49(\mathrm{~s}, 1 \mathrm{H}), 4.94$ (s, 4H). $-{ }^{13} \mathrm{C}$ NMR $(100 \mathrm{MHz}): \delta=31.20,124.61,126.88$, 127.26, 131.61, 134.95 .

4: M.p. $212-214{ }^{\circ} \mathrm{C} .-{ }^{1} \mathrm{H}$ NMR $\left(500 \mathrm{MHz}, \mathrm{CDCl}_{3}\right)$ : $\delta=8.20(\mathrm{~d}, 2 \mathrm{H}), 7.59(\mathrm{t}, 2 \mathrm{H}), 7.54(\mathrm{~d}, 2 \mathrm{H}), 4.96(\mathrm{~s}, 4 \mathrm{H})$. -

${ }^{13} \mathrm{C}$ NMR (100 MHz): $\delta=31.46,125.37,126.03,128.12$, 131.78, 134.21.

5: M.p. $123-126{ }^{\circ} \mathrm{C} .-{ }^{1} \mathrm{H}$ NMR $\left(500 \mathrm{MHz}, \mathrm{CDCl}_{3}\right)$ : $\delta=8.15(\mathrm{~d}, 1 \mathrm{H}), 7.88(\mathrm{~s}, 1 \mathrm{H}), 7.82(\mathrm{~d}, 1 \mathrm{H}), 7.65(\mathrm{~d}, 1 \mathrm{H})$, $7.55(\mathrm{~d}, 1 \mathrm{H}), 7.43(\mathrm{t}, 1 \mathrm{H}), 4.95(\mathrm{~s}, 2 \mathrm{H}), 4.68(\mathrm{~s}, 2 \mathrm{H})$. -

${ }^{13} \mathrm{C}$ NMR $(100 \mathrm{MHz}): \delta=31.51,33.60,124.83,126.23$, $127.64,128.51,128.85,129.91,130.88,133.50,134.02$, 135.72 .

6: M.p. $127-130{ }^{\circ} \mathrm{C} .-{ }^{1} \mathrm{H}$ NMR $\left(500 \mathrm{MHz}, \mathrm{CDCl}_{3}\right)$ : $\delta=8.13(\mathrm{~s}, 1 \mathrm{H}), 7.88(\mathrm{~d}, 1 \mathrm{H}), 7.83(\mathrm{~d}, 1 \mathrm{H}), 7.57$ $(\mathrm{d}, 2 \mathrm{H}), 7.43(\mathrm{t}, 1 \mathrm{H}), 4.96(\mathrm{~s}, 2 \mathrm{H}), 4.73(\mathrm{~s}, 2 \mathrm{H})$.

${ }^{13} \mathrm{C}$ NMR $(100 \mathrm{MHz}): \delta=31.49, \quad 34.22,126.24$,
$127.35,128.52,129.69,129.89,131.05,133.58,133.85$, 136.07 .

7: ${ }^{1} \mathrm{H}$ NMR $\left(500 \mathrm{MHz}, \mathrm{CDCl}_{3}\right): \delta=7.91(\mathrm{~d}, 2 \mathrm{H}), 7.65$ (d, 2H), 7.48 (t, 2H), 5.34 (s, 4H). $-{ }^{13} \mathrm{C}$ NMR (100 MHz): $\delta=37.21,125.74,129.06,131.96,133.08,133.45,136.15$.

8: M. p. $140-143^{\circ} \mathrm{C} .-{ }^{1} \mathrm{H} \mathrm{NMR}\left(500 \mathrm{MHz}, \mathrm{CDCl}_{3}\right): \delta=$ $7.87(\mathrm{bs}, 2 \mathrm{H}), 7.79-7.82$ and $7.50-7.53\left(\mathrm{AA}^{\prime} \mathrm{BB}^{\prime}, 4 \mathrm{H}\right), 4.89$ (4H). $-{ }^{13} \mathrm{C}$ NMR (100 MHz): $\delta=31.18,127.37,127.89$, $130.92,133.45,133.92$.

9: M.p. $182-185{ }^{\circ} \mathrm{C} .-{ }^{1} \mathrm{H}$ NMR $\left(500 \mathrm{MHz}, \mathrm{CDCl}_{3}\right)$ : $\delta=7.84(\mathrm{bs}, 2 \mathrm{H}), 7.83(\mathrm{~d}, 2 \mathrm{H}), 7.55(\mathrm{~d}, 2 \mathrm{H}), 4.68(\mathrm{~s}, 4 \mathrm{H})$. ${ }^{13} \mathrm{C}$ NMR (100 MHz): $\delta=33.76,124.24,127.67,127.70$, 128.83, 132.86, 135.94. 10: M.p. $145-147{ }^{\circ} \mathrm{C} .-{ }^{1} \mathrm{H}$ NMR $\left(500 \mathrm{MHz}, \mathrm{CDCl}_{3}\right): \delta=7.82(\mathrm{~d}, 2 \mathrm{H}), 7.81(\mathrm{~s}, 2 \mathrm{H}), 7.52(\mathrm{~d}$, $2 \mathrm{H}), 4.66(\mathrm{~s}, 4 \mathrm{H}) .-{ }^{13} \mathrm{C} \mathrm{NMR}(100 \mathrm{MHz}): \delta=33.85,127.65$, $128.03,128.74,132.85,133.13,136.01$.

\section{$X$-Ray structure determinations}

Crystal data are summarised in Table 4. Data were registered on a Bruker SMART 1000 CCD diffractometer using $\mathrm{Mo} K_{\alpha}$ radiation at $-140{ }^{\circ} \mathrm{C}$. Absorption corrections were applied using the multi-scan method. Structures were refined using the program SHELXL-97 [16]. Hydrogen atoms were included using a riding model. Crystal quality was good for most samples, but less good for $\mathbf{1 0}$, as is reflected in $e$. $g$. the $R$ values (perhaps by coincidence, $\mathbf{1 0}$ is the only molecule to crystallise with mirror symmetry and it also has the lowest density of all ten isomers, $1.889 \mathrm{~g} \mathrm{~cm}^{-3}$, compared with a maximum of $1.981 \mathrm{~g} \mathrm{~cm}^{-3}$ for 4). Since most badly fitting reflections have $F_{\mathrm{O}}>F_{\mathrm{c}}$, twinning phenomena might be responsible, but no usable twinning model could be developed.

Complete crystallographic data have been deposited at the Cambridge Crystallographic Data Centre under the numbers CCDC $759561-759569$ for compounds 1-6 and 810 in that order. Copies can be obtained free of charge via www.ccdc.cam.ac.uk/data_request/cif.
[1] J. R. Davy, J. A. Reiss, J .Chem. Soc., Chem. Comm. 1973, 806-807.

[2] T. Higashi, K. Uemura, K. Inami, M. Mochizuki, Bioorg. Med. Chem. 2009, 17, $3568-3571$.

[3] P. Kuś, P. G. Jones, Acta Crystallogr. 2003, E59, o8990900.

[4] P. G. Jones, P. Kuś, Acta Crystallogr. 2005, E61, o1235-o1236.

[5] P. G. Jones, P. Kuś, Acta Crystallogr. 2005, E61, o2947-o2948.

[6] P. G. Jones, A. Zemanek, P. Kuś, Acta Crystallogr. 2007, C63, o73-o76.

[7] P. G. Jones, P. Kuś, Z. Naturforsch. 2007, 62b, $725-$ 731.
[8] P. Kuś, A. Zemanek, P. G. Jones, Acta Crystallogr. 2009, E65, o1327.

[9] M. Mazik, A. C. Buthe, P. G. Jones, Tetrahedron 2010, $66,385-389$.

[10] J.-B. Robert, J.S. Sherfinski, R.E. Marsh, J.D. Roberts, J. Org. Chem. 1974, 39, $1152-1156$.

[11] F. H. Allen, Acta Crystallogr. 2002, B58, 380-388.

[12] W. Ried, H. Bodem, Chem. Ber. 1958, 91, $1981-$ 1982.

[13] V. R. Pedireddi, D. S. Reddy, B. S. Goud, D. C. Craig, A. D. Rae, G. R. Desiraju, J. Chem. Soc., Perkin Trans. 2 1994, $2353-2360$.

[14] W.-W. du Mont, M. Bätcher, C. Daniliuc, F. A. Devillanova, C. Druckenbrodt, J. Jeske, P. G. Jones, V. Lip- 
polis, F. Ruthe, E. Seppälä, Eur. J. Inorg. Chem. 2008, $4562-4577$.

[15] G. M. Day, W.D.S. Motherwell, H.L. Ammon, S.X.M. Boerrigter, R. G. Della Valle, E. Venuti, A. Dzyabchenko, J.D. Dunitz, B. Schweizer, B.P. van Eijck, P. Erk, J.C. Facelli, V.E. Bazterra, M. B. Ferraro, D. W. M. Hofmann, F. J. J. Leusen, C. Liang, C. C. Pantelides, P. G. Karamertzanis, S. L. Price, T. C.
Lewis, H. Nowell, A. Torrisi, H. A. Scheraga, Y. A. Arnautova, M. U. Schmidt, P. Verwer, Acta Crystallogr. 2005, B61, $511-527$.

[16] G. M. Sheldrick, SHELXL-97, Program for the Refinement of Crystal Structures, University of Göttingen, Göttingen (Germany) 1997. See also: G. M. Sheldrick, Acta Crystallogr. 2008, A64, $112-$ 122. 